\title{
Prenatal Diagnosis of Proximal Focal Femoral Deficiency: Literature Review of Prenatal Sonographic Findings
}

\author{
Valentina D'Ambrosio, MD, ${ }^{1}$ Gaia Pasquali, $\mathrm{MD},{ }^{2}$ Antonia Squarcella, $\mathrm{MD},{ }^{2}$ Eleonora Marcoccia, $\mathrm{MD},{ }^{2}$ \\ Angela De Filippis, MD, ${ }^{2}$ Silvia Gatto, MD, ${ }^{2}$ Aliberti Camilla, MD, ${ }^{2}$ Antonio Pizzuti, PhD, ${ }^{1}$ \\ Renato La Torre, MD, ${ }^{2}$ Antonella Giancotti, MD $^{2}$ \\ ${ }^{1}$ Department of Experimental Medicine, University of Rome "Sapienza", Umberto I Hospital, Rome, Italy \\ ${ }^{2}$ Department of Obstetrics, Gynecology and Urologic Sciences, University of Rome "Sapienza”, Umberto I Hospital, \\ Rome, Italy
}

Received 10 March 2015; accepted 16 August 2015

\begin{abstract}
Proximal focal femoral deficiency (PFFD) is a rare musculoskeletal malformation that occurs in $0.11-0.2$ per 10,000 live births. This congenital anomaly involves the pelvis and proximal femur with widely variable manifestations, from mild femoral shortening and hypoplasia to the absence of any functional femur and acetabular aplasia. Prenatal diagnosis of PFFD is still a challenge, but early recognition of this malformation could provide useful information to both parents and physicians concerning management and therapeutic planning. For this review, we analyzed all the cases of prenatally diagnosed PFFD that were reported in the literature from 1990 to 2014 and provide a description of the most common prenatal sonographic findings. (C) 2015 Wiley Periodicals, Inc. J Clin Ultrasound 00:000-000, 2015; Published online in Wiley Online Library (wileyonlinelibrary.com). DOI: 10.1002/jcu.22306
\end{abstract}

Keywords: proximal focal femoral deficiency; prenatal diagnosis; musculoskeletal; malformations; fetal ultrasonography

\section{INTRODUCTION}

$\mathrm{P}_{\mathrm{w}}^{\mathrm{r}}$ renatal ultrasound (US) examinations are 1 widely used to screen for fetal anomalies in the general population of pregnant women. Standard US examinations require fetal femur biometry to estimate prenatal growth. ${ }^{1}$ Today, high-resolution

Correspondence to: V. D’Ambrosio

우 2015 Wiley Periodicals, Inc.
US imaging enables the detection of skeletal malformations, which is advantageous for providing genetic counseling and pregnancy management. ${ }^{2}$

Proximal focal femoral deficiency (PFFD), a rare skeletal disorder that occurs in $0.11-0.2$ per 10,000 live births, ${ }^{3,4}$ involves the pelvis and proximal femur with widely variable manifestations. It is the consequence of a failure in normal femur development and can range from limb shortening to a complete absence of the proximal femur and acetabulum. It can cause hip deformity with malfunction of iliofemoral articulation, limb malrotation, and leg length discrepancy. ${ }^{4,5}$ The diagnosis of PFFD is usually made at birth, but if the disturbance is less obvious, it may not be diagnosed until the child begins to walk. ${ }^{5,6}$ Its bilateral manifestation is rare; the unilateral form occurs in $85-90 \%$ of cases. The malformation is sporadic, but familial cases have been reported. ${ }^{7,8}$ Several etiologic factors for PFFD have been proposed, including poorly controlled diabetes, drug exposure, viral infections, radiation exposure, focal ischemia, chemical toxicity, and trauma between the fourth and eighth weeks of gestation. ${ }^{9-11}$ The disorder is not related to mental impairment and chromosomal abnormalities. ${ }^{12}$

Different classification systems have been proposed to stratify PFFD. The most widely used is Aikten's classification, ${ }^{13}$ which separates this disorder into four categories according to the severity of the findings: the presence or absence of cartilaginous continuity of the proximal femur and development of the hip joint. Another 
D’AMBROSIO ET AL

TABLE 1

Two Classification Systems for Proximal Focal Femoral Deficiency

\begin{tabular}{|c|c|c|c|c|}
\hline \multicolumn{2}{|c|}{ Classification System } & \multicolumn{3}{|c|}{ Anatomic Feature } \\
\hline Aikten $^{13}$ & Amstutz $^{4}$ & Femoral Head & Acetabulum & Femoral Segment \\
\hline \multirow{2}{*}{ A } & 1 & Present & Coxa vara & Short \\
\hline & 2 & $\begin{array}{l}\text { Subtrochanteric } \\
\text { pseudoarthrosis }\end{array}$ & Normal & Short \\
\hline $\mathrm{B}$ & 3 & Present & $\begin{array}{l}\text { Adequately developed or } \\
\text { moderately dysplastic }\end{array}$ & $\begin{array}{c}\text { Short, usually proximal } \\
\text { bony tuft }\end{array}$ \\
\hline $\mathrm{C}$ & 4 & Absent or very small & Severely dysplastic & $\begin{array}{c}\text { Short, usually proximally } \\
\text { tapered }\end{array}$ \\
\hline $\mathrm{D}$ & 5 & Absent & Absent & Short, deformed \\
\hline
\end{tabular}

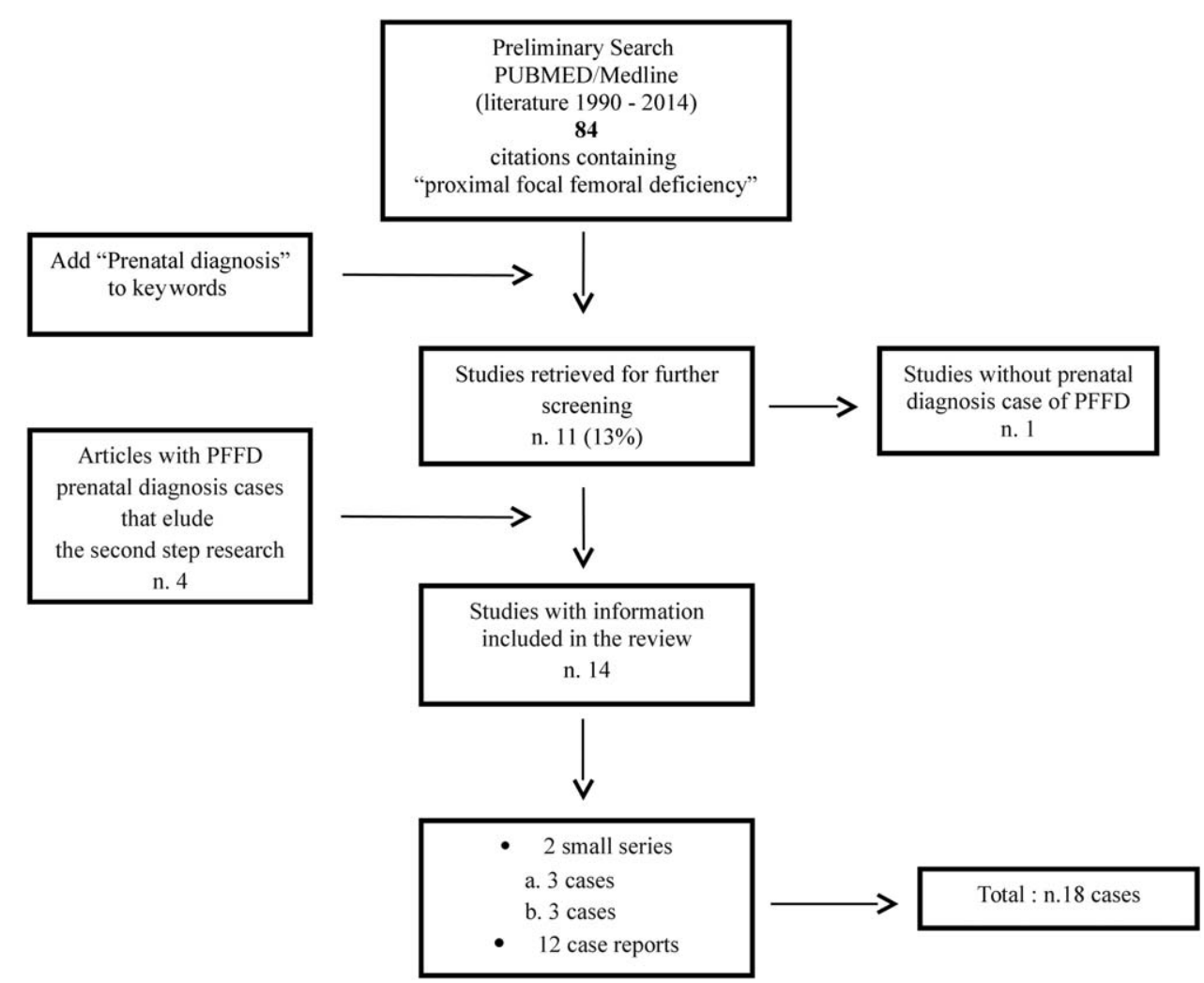

FIGURE 1. Flow chart depicts the search strategy we used in our systematic literature review for prenatally diagnosed cases of proximal focal femoral deficiency (PFFD).

classification system, proposed by Amstutz, ${ }^{4}$ separates all the anatomic types, from a mild degree of femoral hypoplasia to subtotal absence of the femur (Table 1). Although radiography is the first imaging technique used to evaluate the grade of PFFD, MRI is useful in classifying a case as a definitive subtype and seems to be more accurate for predicting the prognosis and guiding surgery. ${ }^{14}$ Treatment for PFFD depends on the degree of discrepancy in leg length. ${ }^{7,15}$

Prenatally diagnosing PFFD is still a challenge, but early recognition of this malformation could provide useful information to both parents and physicians concerning management and therapeutic planning. In an attempt to provide a description of the most common findings of PFFD on prenatal US examination, we performed this review of all cases of prenatally diagnosed PFFD that were reported in the literature from 1990 through 2014.

\section{METHODS}

We searched PubMed, EMBASE, Medline, and reference lists to identify articles published from 
TABLE 2

Summary of Demographic, Obstetric, Imaging, and Outcome Characteristics of 18 Published Cases of Prenatally Diagnosed Proximal Focal Femoral Deficiency

\begin{tabular}{|c|c|}
\hline Characteristic & $\begin{array}{c}\text { No. of Patients } \\
(\%)^{*}\end{array}$ \\
\hline Mean maternal age, years (range) & $33(24-39)$ \\
\hline Mean GA at diagnosis, weeks (range) & $23(14-35)$ \\
\hline \multicolumn{2}{|l|}{ Race or ethnicity } \\
\hline \multirow[t]{2}{*}{ Reported } & $2(11)$ \\
\hline & (Japanese, Muslim) \\
\hline Not reported & $16(89)$ \\
\hline \multicolumn{2}{|l|}{ Parity } \\
\hline Nulliparous & $2(11)$ \\
\hline Multiparous & $11(61)$ \\
\hline Not reported & $5(28)$ \\
\hline \multicolumn{2}{|l|}{ Risk factor } \\
\hline Yes & 2 (11) (Diabetes) \\
\hline No & $16(89)$ \\
\hline \multicolumn{2}{|l|}{ Trimester at initial US finding } \\
\hline First & 0 \\
\hline Second & $15(83)$ \\
\hline Third & $3(17)$ \\
\hline \multicolumn{2}{|l|}{$\begin{array}{l}\text { Invasive procedures } \\
\text { performed for karyotyping }\end{array}$} \\
\hline Yes & $5(28)$ \\
\hline No & $13(72)$ \\
\hline \multicolumn{2}{|c|}{ Imaging modality used for prenatal diagnosis } \\
\hline US & $17(94.4)$ \\
\hline $\mathrm{US}+\mathrm{CT}$ & $1(5.6)$ \\
\hline \multicolumn{2}{|l|}{ Fetal outcome } \\
\hline Elective termination of pregnancy & $8(44)$ \\
\hline Cesarean section delivery & $3(17)$ \\
\hline \multirow[t]{2}{*}{ Vaginal delivery } & $7(39)$ \\
\hline & (1 preterm) \\
\hline \multicolumn{2}{|c|}{ Imaging modality used for postnatal examination } \\
\hline Radiograph & $10(55.6)$ \\
\hline Radiograph $+\mathrm{MRI}$ & $1(5.6)$ \\
\hline Radiograph $+\mathrm{MRI}+\mathrm{US}$ & $1(5.6)$ \\
\hline Radiograph + arteriography & $1(5.6)$ \\
\hline Not reported & $4(22)$ \\
\hline Not possible & $1(5.6)$ \\
\hline
\end{tabular}

Abbreviations: GA, gestational age; US, ultrasound. *Unless otherwise specified.

January 1990 through December 2014 that described the prenatal diagnosis of PFFD. The preliminary search was performed using "proximal focal femoral deficiency" as keywords. In a second step, the keyword "prenatal diagnosis" was added to the search terms.

Our criteria for including reports in our analysis were a singleton pregnancy, a prenatal diagnosis of PFFD, information about the imaging technique used for the prenatal investigation, and the presence of data about the fetal and/or neonatal outcomes. Reports were excluded from our study if at least one inclusion criterion was omitted or if the diagnosis of a short femur was related to different syndromes.

Maternal characteristics and obstetric and outcome data were also extracted. We then analyzed the individual US findings and other prenatal characteristics to identify any features or patterns that may facilitate making a correct prenatal diagnosis of PFFD.

\section{RESULTS}

Our preliminary literature search identified 84 publications. When we added the keywords "prenatal diagnosis," we obtained 11 results. One study that described a postnatally diagnosed case of PFFD was excluded from the review. We added to our analysis four further articles that had eluded the second step of our search but did meet the review inclusion criteria. In total, we included 14 qualifying studies, with a final population of 18 patients, in our analysis (Figure 1).

The patients' general and obstetric characteristics are summarized in Table 2 . The mean gestational age of the fetuses at the time of the first US finding was 23 weeks (range, 14-35 weeks). PFFD was suspected in the second trimester in 15 of the 18 cases (83\%); in the remaining three (17\%), the suspicion did not arise until the third trimester. No cases were identified in the first trimester. Invasive procedures for karyotyping were performed on five patients (28\%), and in all five, the results were normal.

The prenatal diagnosis was made using only the US results in 17 of the 18 cases (94\%); in the other one $(6 \%)$, three-dimensional $\mathrm{CT}$ was also used. A short femur was found bilaterally in 4 of the 18 patients (22\%) and unilaterally in the remainder $(78 \%)$. The defect was isolated in 10 patients $(55.5 \%)$, whereas other skeletal anomalies were also present in seven (39\%), and one fetus (5.5\%) had ventriculomegaly and oligohydramnios. The other skeletal anomalies included three cases of a bowed ipsilateral tibia, four cases of agenesis of the ipsilateral fibula, three cases of clubfoot, and one case of a twisted ipsilateral foot. In one case, oligodactyly of the right hand was noted (Table 3). ${ }^{1-3,10,11,16-24}$

Elective pregnancy termination was performed in 8 of the 18 women (44\%). Among the remainder, three patients (17\%) delivered by cesarean section at term, and seven (39\%) delivered vaginally, 1 of whom had a preterm vaginal delivery (33 weeks) for premature membrane rupture. Postnatal examination confirmed the prenatal diagnosis of PFFD in 16 cases (89\%); in one case (5.5\%), a femoral--facial syndrome (FFS) was found, and in one $(5.5 \%)$ case, postnatal analysis was not possible. In 10 of the 18 cases (56\%), a postnatal diagnosis was made only on radiograph (XR); in one 
TABLE 3

Prenatal Sonographic Findings in Fetuses with Proximal Focal Femoral Deficiency Reported in Literature 1990-2014: Associated Skeletal and Nonskeletal Anomalies

\begin{tabular}{|c|c|c|c|c|c|c|c|c|}
\hline Case & $\begin{array}{l}\text { Publication, } \\
\text { Reference No. }\end{array}$ & $\begin{array}{c}\text { Unilateral or } \\
\text { Bilateral }\end{array}$ & Tibia & Fibula & Foot & $\begin{array}{c}\text { Other Skeletal } \\
\text { Anomalies }\end{array}$ & Face & $\begin{array}{c}\text { Other } \\
\text { Anomalies }\end{array}$ \\
\hline 1 & $\begin{array}{c}\text { Ashkenazy et al, } \\
1990^{11}\end{array}$ & $u$ & N & $\mathrm{N}$ & $\mathrm{N}$ & No & Not reported & No \\
\hline 2 & $\begin{array}{l}\text { Bronstein and } \\
\text { Deutsch, } 1992^{16}\end{array}$ & $u$ & N & $\mathrm{N}$ & $\mathrm{N}$ & No & Not reported & $\begin{array}{c}\text { Ventriculome- } \\
\text { galy, } \\
\text { Oligoamnios }\end{array}$ \\
\hline 3 & $\begin{array}{c}\text { Camera et al, } \\
1993^{17}\end{array}$ & $u$ & bowed & absent & $\mathrm{N}$ & No & Not reported & No \\
\hline 4 & $\begin{array}{c}\text { Hadi and Wade, } \\
1993^{10}\end{array}$ & $u$ & N & $\mathrm{N}$ & clubfoot & No & Not reported & No \\
\hline 5 & $\begin{array}{c}\text { Gonçalves et al, } \\
1996^{18}\end{array}$ & B & N & $\mathrm{N}$ & $\mathrm{N}$ & No & Not reported & No \\
\hline 6 & $\begin{array}{c}\text { La Torre et al, } \\
2003^{19}\end{array}$ & $u$ & N & absent & Twisted right foot & No & Not reporter & No \\
\hline 7 & $\begin{array}{l}\text { Filly et al, } \\
2004^{20}\end{array}$ & U & bowed & absent & $\mathrm{N}$ & No & $\mathrm{N}$ & No \\
\hline 8 & & B & $\mathrm{N}$ & $\mathrm{N}$ & clubfoot & No & $\mathrm{N}$ & No \\
\hline 9 & & B & bowed & absent & clubfoot & No & $\mathrm{N}$ & No \\
\hline 10 & $\begin{array}{l}\text { Cuillier et al, } \\
2005^{2}\end{array}$ & U & $\mathrm{N}$ & $\mathrm{N}$ & $\mathrm{N}$ & No & $\mathrm{N}$ & No \\
\hline 11 & $\begin{array}{l}\text { Parakh and } \\
\text { Nagar, } 2006^{21}\end{array}$ & U & N & $\mathrm{N}$ & $\mathrm{N}$ & No & Not reported & No \\
\hline 12 & Oh et al, $2008^{1}$ & $u$ & $\mathrm{~N}$ & $\mathrm{~N}$ & $\mathrm{~N}$ & No & Not reported & No \\
\hline 13 & & $u$ & $\mathrm{~N}$ & $\mathrm{~N}$ & $\mathrm{~N}$ & No & Not reported & No \\
\hline 14 & & u & $\mathrm{N}$ & $\mathrm{N}$ & $\mathrm{N}$ & No & Not reported & No \\
\hline 15 & $\begin{array}{l}\text { Otera et al, } \\
2009^{22}\end{array}$ & B & N & $\mathrm{N}$ & $\mathrm{N}$ & $\begin{array}{l}\text { Oligodactyly of } \\
\text { right hand }\end{array}$ & $\mathrm{N}$ & No \\
\hline 16 & $\begin{array}{l}\text { Mailath- } \\
\text { Pokorny et al, } \\
2011^{23}\end{array}$ & U & $\mathrm{N}$ & $\mathrm{N}$ & $\mathrm{N}$ & No & $\mathrm{N}$ & No \\
\hline 17 & Lin et al, $2013^{3}$ & $u$ & N & $\mathrm{N}$ & $\mathrm{N}$ & No & $\mathrm{N}$ & No \\
\hline 18 & $\begin{array}{l}\text { Doğer et al, } \\
2013^{24}\end{array}$ & U & N & $\mathrm{N}$ & $\mathrm{N}$ & No & $\mathrm{N}$ & No \\
\hline
\end{tabular}

Abbreviations: $U$, unilateral; $\mathrm{N}$, normal; $\mathrm{B}$, bilateral.

case $(5.5 \%)$, on XR and MRI; in one (5.5\%), on XR, MRI, and US; and in one (5.5\%), on XR and aortoarteriography. In another four (22\%), the imaging techniques used for postnatal diagnosis were not described.

\section{DISCUSSION}

Prenatal diagnosis of skeletal dysplasia is a major challenge for obstetric US examination because one must rule out a long list of possible disorders---more than 200---in considering the differential diagnosis (DD). ${ }^{18}$ However, improvements in US imaging technology have given sonographers important tools to use in recognizing and differentiating even the rarest skeletal malformations. Through our data analysis, we could identify the most common features of PFFD found on US examination, which can be useful for making a prenatal diagnosis.

The most common prenatal finding in the case of unilateral PFFD is a difference in the biometry of the two femora. ${ }^{18}$ US imaging allows the detection of subtle discrepancies in the length of long bones between the right and left sides. ${ }^{24}$ This skeletal alteration may be the only sign of the disease. In many cases described in the literature (30-60\%), other bony abnormalities were associated with PFFD, including fibular agenesis (22\%), clubfoot deformity (17\%), and bowed tibia (17\%) (Figure 2). Oligodactyly was also reported as an associated manifestation. ${ }^{22}$ In the bilateral form of PFFD, the femora may both be short but with varying degrees of severity.

The diagnosis is usually possible during the second trimester of pregnancy. Earlier, the identification of femoral hypoplasia is less feasible because discrepancies between the measurements of the femora may consist of only a few millimeters, a difference that is not easily detectable. ${ }^{2,16,17,20}$ However, the suspicion of a severe manifestation of the disorder may arise in the first trimester; in such cases, we suggest the use of the transvaginal approach to US, 

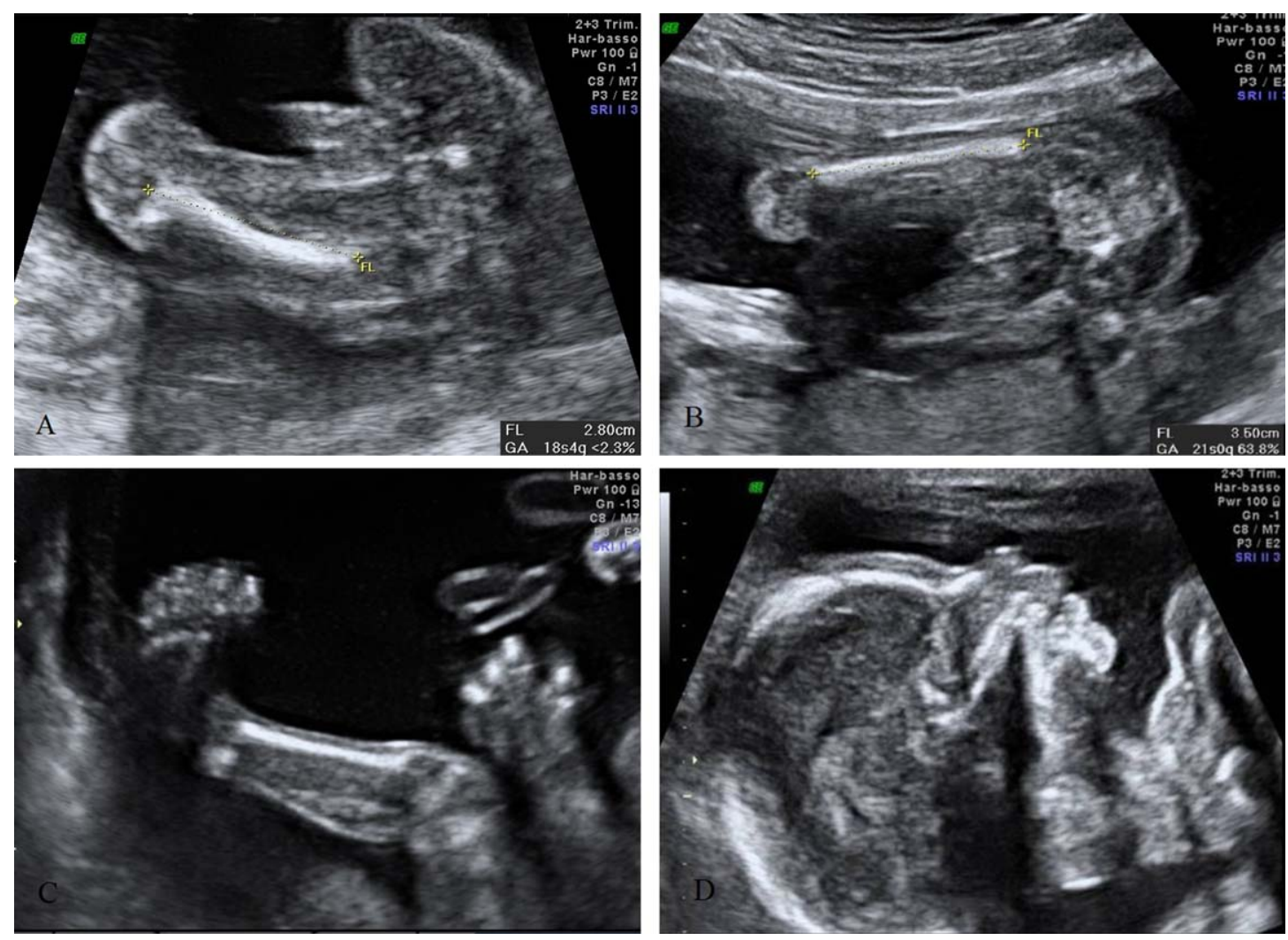

FIGURE 2. Sonograms depict fetal unilateral proximal focal femoral deficiency (PFFD) associated with other skeletal anomalies. (A) Twodimensional sonogram depicts a short left femur. (B) Two-dimensional sonogram shows a normal right femur. FL, femur length; GA, gestational age. (C) Two-dimensional sonogram of the left lower extremity demonstrates fibular agenesis and clubfoot. (D) Mid-sagittal view shows a normal fetal profile.

which allows the greatest accuracy in long bone measurement during the first trimester. ${ }^{16}$

If PFFD is suspected prenatally, it is mandatory to consider the other possible disorders in making a DD, because a short femur could be the first sign of many forms of skeletal dysplasia. $^{25}$ In the bilateral form of PFFD, one should also consider kyphomelic dysplasia, campomelic dysplasia, osteogenesis imperfecta, achondroplasia, achondrogenesis, thanatoforic dysplasia, and short limb polydactyly., ${ }^{3,26}$ To exclude these global dysplasias, one must measure all of the other long bones and explore the chest, spine, and skull, which are often compromised. If they appear normal, the diagnosis of bilateral PFFD should be highly suspected. Moreover, in PFFD, demineralization is never described. ${ }^{22}$

Three other rare overlapping conditions that involve femoral development must also be excluded, especially in the unilateral form of PFFD: the femur-fibula-ulna (FFU) complex, the FFS, and limb/pelvis-hypoplasia/aplasia syndromes. ${ }^{2,3,20,24}$ The FFU complex is a sporadic limb disorder involving the femur, fibula, and ulna in highly variable combinations. A further typical feature is the association of finger and/or toe anomalies. All malformations of the FFU complex are most often unilateral, and the right side is more commonly involved. It occurs more frequently in males than in females (M:F ratio, 1.9). ${ }^{27}$ Some authors have stated that the FFU complex and PFFD are the same entity, but others consider them to be two separate conditions. ${ }^{23,28}$ In general, if the upper extremities are normal, the FFU complex can be excluded.

The FFS is a rare condition characterized by unilateral or bilateral femoral hypoplasia that is associated with facial dimorphism that can range from evident micrognathia with or without a cleft lip and/or palate to more subtle features, such as upslanting palpebral fissures, a short nose with a broad tip, a long philtrum, a thin upper lip, maxillary asymmetry, and an isolated cleft palate. Additional malformations have been described occasionally in neonates, including genitourinary and central nervous system anomalies. ${ }^{29}$ Sometimes the diagnosis of FFS is made after delivery because prenatal detection of a subtle facial defect is not guaranteed; therefore, we suggest 


\section{D’AMBROSIO ET AL}

careful exploration of the fetal face on twodimensional imaging and, if it is available, taking advantage of three-dimensional imaging. Today's high-quality three-dimensional sonography may be able to show more subtle facial aberrations. ${ }^{30}$ If the fetal profile looks normal, FFS should be excluded.

The limb/pelvis-hypoplasia/aplasia syndrome, also known as the Al-Awadi/Raas-Rothschild syndrome, is a rare autosomal-recessive disorder that is characterized by severe skeletal malformations involving the upper and lower extremities and the pelvis. Additional features may include thoracic dystrophy, unusual facies (eg, dysplastic and large ears, high and narrow palate), and genital malformations. ${ }^{31}$ It is easy to distinguish between the limb/pelvis-hypoplasia/aplasia syndrome and PFFD because the latter does not usually manifest with secondary skeletal deformities, and the primary problem is short and unequal femur lengths. Additional imaging techniques could be used for prenatal investigation in suspected cases of PFFD for example, in one case reported in the publications we reviewed, helical CT was performed for a better evaluation of the disease severity. That imaging modality allows the identification of such associated features as absence of the femoral head, hip dislocation, acetabular dysplasia, and oligodactyly. ${ }^{22}$ In one recent study, Macé et $\mathrm{al}^{32}$ considered helical CT with threedimensional reconstruction to be a key examination in diagnosing skeletal dysplasia after 26 weeks' gestation, when fetal ossification has reached a good level. (The issues related to irradiation's being detrimental for the fetus are overcome by the low dose used [2-3 mGy], which is far from the $100 \mathrm{mGy}$ considered potentially teratogenic in international recommendations. ${ }^{33}$ ) Macé et $\mathrm{al}^{32}$ suggested reserving helical CT for cases of severe micromelia in the presence of associated skeletal signs, and when the results of standard cytogenetic, virologic, and molecular examinations are negative.

We suppose that in the future, fetal MRI could contribute to making a diagnosis of complex skeletal dysplasia, especially when joints are involved. To date, innovations in sequence technologies and results of animal studies have been promising. Further research on fetal MRI, including technical refinements and clinical studies, will be necessary. ${ }^{34}$

When a PFFD is identified prenatally, physicians should exclude the possibility of teratogenic and vascular insults from the fourth to eighth weeks of gestation, the critical period in limb development. ${ }^{1}$ There is no need to alter standard pregnancy management because the disease is not associated with obstetric complications. Multidisciplinary counseling of the parents is mandatory, however, and should involve an expert in fetal medicine, a geneticist, and a pediatric orthopedist. Parents should be reassured that PFFD is not related to chromosomal defects and does not impair intelligence. ${ }^{18}$ Orthopedic management is highly individualized and depends on the developmental pattern of the length discrepancy; it may require surgical correction or amputation and a prosthesis, but the long-term prognosis after orthopedic correction is good. ${ }^{7,15}$ In countries where abortion is legal, and when the condition is demonstrated to be severe, the option of pregnancy termination may be offered to the family.

The data we analyzed for this review confirmed that a prenatal diagnosis of PFFD is possible and revealed what the most common US findings are. We suggest that all sonographers be cautious and not hasty in diagnosing this disease, considering its low frequency. When a short femur is found, one must consider potential sources of errors in measurement. First, it is important to pay attention to the inclination angle of the transducer: if the measurement is taken on an oblique plane, a difference varying from $4-10 \mathrm{~mm}$ is probable. ${ }^{35}$ It is also possible that one end of the bone is shadowed by another bony fetal segment. ${ }^{10}$ When measuring femur length, one should follow the international US guidelines: a scan must clearly visualize both ends of the ossified metaphysis with the probe perpendicular to the longest axis of the femur (angle inclination between 45 and 90 degrees). The calipers must be placed at both ends of the ossified diaphysis, excluding the distal femoral epiphysis if it is visible. This measurement should also exclude triangular spur artifacts, which can falsely extend the length of the diaphysis. ${ }^{36}$ If isolated short femurs are found bilaterally, one should initially consider more common etiologic factors, including ethnic variation, soft markers for aneuploidies, or fetal growth restriction. ${ }^{1}$ If all of these conditions (including those previously analyzed for making a DD) were to be excluded, the suspicion of PFFD could fairly arise.

We conclude that although subtle cases of PFFD will likely continue to go undetected, given experienced examiners and advances in US imaging technology, a prenatal diagnosis is feasible in most cases. Prenatal US findings are important in stratifying cases of PFFD according to severity. Early 
recognition of this condition will not only prepare the parents but also yield information for physicians specifically concerning the management, therapeutic planning, and long-term follow-up of affected fetuses.

\section{ACKNOWLEDGMENTS}

We thank Dr. Earli Bardhi for revising the English in the manuscript.

\section{REFERENCES}

1. Oh KY, Frias AE Jr, Byrne JL, et al. Unilateral short femur---what does this mean? Report of 3 cases. Ultrasound Q 2008;24:89.

2. Cuillier F, Cartault F, Moreau ML, et al. Antenatal presentation of isolated femoral hypoplasia discovered at 18 weeks of gestation. Fetal Diagn Ther 2005;20:197.

3. Lin TH, Chung CH, Shih JC, et al. Prenatal diagnosis of proximal femoral focal deficiency: a case report and literature review. Taiwan J Obstet Gynecol 2013;52:267.

4. Amstutz HC. The morphology, natural history, and treatment of proximal femoral deficiencies. In: Aitken GT, editor. Proximal Femoral Focal Deficiency: A Congenital Anomaly. Washington, DC: National Academy of Sciences; 1996, p 50e76.

5. Dillon JE, Connolly SA, Connolly LP, et al. MR imaging of congenital/developmental and acquired disorders of the pediatric hip and pelvis. Magn Reson Imaging Clin N Am 2005;13:783.

6. Anton CG, Applegate KE, Kuivila TE et al. Proximal femoral focal deficiency (PFFD): more than an abnormal hip. Semin Musculoskelet Radiol 1999;3: 215.

7. Jeanty P, Kleinman G. Proximal femoral focal deficiency. J Ultrasound Med 1989;8:639.

8. Keret D, Timor IE. Pediatric update \#4. Familial congenital short femur: intrauterine detection and follow-up by ultrasound. A case report. Orthop Rev 1988;17:500.

9. Hamanishi C. Congenital short femur. Clinical, genetic and epidemiological comparison of the naturally occurring condition with that caused by thalidomide. J Bone Joint Surg Br 1980;62:307.

10. Hadi HA, Wade A. Prenatal diagnosis of unilateral proximal femoral focal deficiency in diabetic pregnancy: a case report. Am J Perinatol 1993;10:285.

11. Ashkenazy M, Lurie S, Ben-Itzhak I, et al. Unilateral congenital short femur: a case report. Prenat Diagn 1990;10:67.

12. Bevan-Thomas WH, Millar EA. A review of proximal focal femoral deficiencies. J Bone Joint Surg Am 1967;49:1376.

13. Aikten GT. Proximal focal femoral deficiency: definition, classification and management. In: Aikten GT, editor. Proximal Focal Femoral Deficiency: A
Congenital Anomaly. Washington, DC: National Academy of Sciences; 1969, p 1.

14. Maldjian C, Patel TY, Klein RM, et al. Efficacy of MRI in classifying proximal focal femoral deficiency. Skeletal Radiol 2007;36:215.

15. Westberry DE, Davids JR. Proximal focal femoral deficiency (PFFD): management options and controversies. Hip Int 2009;19:18.

16. Bronstein M, Deutsch M. Early diagnosis of proximal femoral deficiency. Gynecol Obstet Invest 1992;34:246.

17. Camera G, Dodero D, Parodi M, et al. Antenatal ultrasonographic diagnosis of a proximal femoral focal deficiency. J Clin Ultrasound 1993;21:475.

18. Gonçalves LF, De Luca GR, Vitorello DA, et al. Prenatal diagnosis of bilateral proximal femoral hypoplasia. Ultrasound Obstet Gynecol 1996;8: 127.

19. La Torre R, Mastrone M, Coacci F, et al. Severe hypoplasia of the right femur, ipsilateral agenesia of the fibula and twisted right foot in a 24-week-old fetus with proximal femoral focal deficiency (PFFD). Clin Exp Obstet Gynecol 2003;30:65.

20. Filly AL, Robnett-Filly B, Filly RA. Syndromes with focal femoral deficiency: strengths and weaknesses of prenatal sonography. J Ultrasound Med 2004;23:1511.

21. Parakh A, Nagar G. Proximal femoral focal deficiency. Indian Pediatr 2006;43:349.

22. Otera Y, Morokuma S, Yumoto Y, et al. Prenatal three-dimensional images of proximal focal femoral deficiency produced by helical computed tomography. Fetal Diagn Ther 2009;25:349.

23. Mailath-Pokorny M, Timor-Tritsch IE, Monteagudo A, et al. Prenatal diagnosis of unilateral proximal femoral focal deficiency at 19 weeks' gestation: case report and review of the literature. Ultrasound Obstet Gynecol 2011;38:594.

24. Doğer E, Köpük SY, Cakıroğlu Y, et al. Unilateral isolated proximal femoral focal deficiency. Case Rep Obstet Gynecol 2013:637904, 2013.

25. Filly RA, Golbus MS, Carey JC, et al. Short-limbed dwarfism: ultrasonographic diagnosis by mensuration of fetal femoral length. Radiology 1981;138: 653.

26. Alanay Y, Krakow D, Rimoin DL, et al. Angulated femurs and the skeletal dysplasias: experience of the International Skeletal Dysplasia Registry (1988-2006). Am J Med Genet A 2007;143A:1159.

27. Geipel A, Berg C, Germer U, et al. Prenatal diagnosis of femur-fibula-ulna complex by ultrasound examination at 20 weeks of gestation. Ultrasound Obstet Gynecol 2003;22:79.

28. Orphanet. Femur-fibula-ulna complex. Orpha2019. Available at: http://www.orpha.net/consor/cgi-bin/ OC_Exp.php?Lng $=$ GB\&Expert $=2019$. Accessed on 22 January 2015.

29. Silvas E, Rypens F, Jovanovic M, et al. Prenatal diagnosis of femoral-facial syndrome: report of two cases. Birth Defects Res A Clin Mol Teratol 2013; 97:770. 
30. Merz E, Abramovicz J, Baba K, et al. 3D imaging of the fetal face---recommendations from the International 3D Focus Group. Ultraschall Med 2012; $33: 175$.

31. Gupta N, Kabra M. Limb/pelvis-hypoplasia/aplasia syndrome---further delineation of phenotype. Fetal Pediatr Pathol 2011;30:355.

32. Macé G, Sonigo P, Cormier-Daire V, et al. Threedimensional helical computed tomography in prenatal diagnosis of fetal skeletal dysplasia. Ultrasound Obstet Gynecol 2013;42:161.
33. The 2007 recommendations of the International Commission on Radiological Protection. ICRP publication 103. Ann ICRP 2007;37:1.

34. Nemec SF, Nemec U, Brugger PC, et al. Skeletal development on fetal magnetic resonance imaging. Top Magn Reson Imaging 2011;22:101.

35. Lessoway VA, Schulzer M, Wittmann BK. Sonographic measurement of the fetal femur: factors affecting accuracy. J Clin Ultrasound 1990;18:471.

36. Salomon LJ, Alfirevic Z, Berghella V, et al. Practice guidelines for performance of the routine midtrimester fetal ultrasound scan. Ultrasound Obstet Gynecol 2011;37:116. 